\title{
Implementation strategies to increase access and demand of long-lasting insecticidal nets: a before-and-after study and scale-up process in Mozambique
}

\author{
Jorge A. H. Arroz ${ }^{1 *}$, Chandana Mendis ${ }^{1}$, Liliana Pinto ${ }^{1}$, Baltazar Candrinho ${ }^{2}$, João Pinto ${ }^{3}$ \\ and Maria do Rosário O. Martins ${ }^{3}$
}

\begin{abstract}
Background: The universal coverage bed nets campaign is a proven health intervention promoting increased access, ownership, and use of bed nets to reduce malaria burden. This article describes the intervention and implementation strategies that Mozambique carried out recently in order to improve access and increase demand for longlasting insecticidal nets (LLINs).

Methods: A before-and-after study with a control group was used during Stage I of the implementation process. The following strategies were tested in Stage I: (1) use of coupons during household registration; (2) use of stickers to identify the registered households; (3) new LLIN ascription formula (one LLIN for every two people). In Stage II, the following additional strategies were implemented: (4) mapping and micro-planning; (5) training; and (6) supervision. Odds ratio (OR) and 95\% confidence interval (Cl) were used to compare and establish differences between intervened and control districts in Stage I. Main outcomes were: percentage of LLINs distributed, percentage of target households benefited.

Results: In Stage I, 87.8\% (302,648) of planned LLINs were distributed in the intervention districts compared to $77.1 \%$ $(219,613)$ in the control districts [OR: $2.14(95 \% \mathrm{Cl} 2.11-2.16)$ ]. Stage I results also showed that $80.6 \%(110,453)$ of households received at least one LLIN in the intervention districts compared to $72.8 \%(87,636)$ in the control districts [OR: $1.56(95 \% \mathrm{Cl} 1.53-1.59)]$. In Stage II, 98.4\% $(3,536,839)$ of the allocated LLINs were delivered, covering $98.6 \%$ $(1,353,827)$ of the registered households.

Conclusions: Stage I results achieved better LLINs and household coverage in districts with the newly implemented strategies. The results of stage II were also encouraging. Additional strategies adaptation is required for a wide-country LLIN campaign.
\end{abstract}

Keywords: Before-and-after design, Implementation strategies, Implementation study, Long-lasting insecticidal nets, Universal coverage bed nets campaign, Mozambique

\section{Background}

In 2015, an estimated 212 million cases of malaria occurred worldwide [1]. Most of the cases in 2015 were in the African Region (90\%) [1]. In the same year, it was

\footnotetext{
*Correspondence: jarroz2010@gmail.com

${ }^{1}$ World Vision International, Maputo, Mozambique

Full list of author information is available at the end of the article
}

estimated that there were 429,000 deaths from malaria globally with an estimated $92 \%$ of deaths occurring in the African region [1]. In Mozambique, malaria is a high burden disease, with a prevalence of $40.2 \%$ in children between 6 and 59 months of age [2]. The effective use of long-lasting insecticidal nets (LLINs) can reduce all-cause child mortality (by 22\%) and malaria morbidity $[3,4]$, and is also associated with a community-wide 
decrease in malaria transmission [5]. The current challenge is to ensure access and ownership of LLINs in order for at least $80 \%$ of the population (and households) to be covered, and make appropriate use of them [6]. Universal coverage campaigns (hereinafter referred to as UCC) are widely proven to be a health intervention that can rapidly overcome the low LLIN access and ownership coverage [7], and are the most cost-effective malaria intervention $[8,9]$.

In 2015 66\% of households in Mozambique had at least one LLIN, and 39\% of households had one LLIN for each two persons [2]. These figures are considered as low coverage when compared with the target of at least $80 \%$ of households with sufficient LLINs to achieve universal coverage (i.e. one LLIN for every two persons) [6]. Therefore, implementation strategies were put in place in campaigns to improve LLIN distribution and reach the desired targets. These strategies were based on the findings that campaigns that make use of vouchers or coupons have better LLIN ownership outcomes [10-15].

This study reports the intervention and implementation strategies that Mozambique carried out in order to improve access and increase demand for LLIN use. A set of implementation strategies is described over two distinct stages: Stage I-a small pilot study in two rural districts; Stage II-a massive pilot in one northeast Mozambican province. The following research questions were addressed: are implementation outcomes changing with the new strategies compared with the old strategies? Which lessons can be learned from the implementation process?

\section{Methods}

\section{Study design}

Stage I was undertaken between October and December 2015. Using a before-after design, the pilot was carried out in four rural districts:

- Intervention districts: Gurue (intervention 1) and Sussundenga (intervention 2), in Zambezia and Manica provinces, respectively;

- Control districts: Alto-Molocue (control 1) and Machaze (control 2), also in Zambezia and Manica provinces, respectively.

This pilot tested a few innovations and adaptations of the model in place for UCC, namely: using coupons to do household registration, using stickers to identify registered households, and a new LLIN ascription criterionone LLIN for every two persons. These innovations and adaptations led to higher coverage of outcome indicators in Stage I (see results section), guiding a massive pilot of the intervention and strategies in Stage II.
Stage II was carried out in the 23 districts of Nampula province (a northeast province of Mozambique, and the most populated of the country). During this stage complementary components of the strategy were added in order to improve planning and implementation processes. This was done with the technical support of Alliance for Malaria Prevention (AMP). Lessons learned from this massive pilot were used to better understand implementation challenges, and guide the country-wide UCC.

\section{Rationale of selection}

Malaria is endemic in Mozambique, with a prevalence of $40.2 \%$ in children between 6 and 59 months of age [2]. The central and northern provinces of Zambezia and Nampula have the highest prevalence (67.9 and 66.0\%, respectively), and the southern provinces of Maputo province and Maputo city have the lowest prevalence (2.8 and $2.2 \%$, respectively) [2]. Manica province has a prevalence of $25.5 \%$ [2] (Fig. 1).

The interventions and controls districts were selected based on the following pragmatic and matching criteria: (i) they would benefit from the LLIN UCC in the concerned period; (ii) have population size similarities (intervention 1 with control 1, and intervention 2 with control 2); (iii) they have similar numbers of LLINs allocated for distribution (intervention 1 with control 1, and intervention 2 with control 2); (iv) they have rural characteristics; and (v) they are districts in provinces with high malaria prevalence.

\section{Description of study setting}

Mozambique is mostly a rural country, with an estimated $5,058,763$ households having an average of 5.0 members per household [16] resulting in an estimated 25,293,815 inhabitants. The illiteracy rate is $44.9 \%$ and most prevalent in the rural area [16]. Sixty-eight percent of the population have easy access to a health facility, i.e., walking less than 30 min to reach a health facility. However, this access is lower in rural areas [16]. The major malaria burden in Mozambique is in the central and northern provinces of Zambezia and Nampula [2, 17]. Nampula province has an estimated 1,016,455 households with an average 4.8 members per household [16] resulting in an estimated 4,878,984 inhabitants.

\section{Description of the health intervention}

The universal coverage LLINs campaign is a proven health intervention promoting increased access, ownership, and use of LLINs to reduce malaria morbidity and mortality [7-9]. The current LLIN campaign in Mozambique has several phases related to trainings at provincial and district level, household registration, and LLIN distribution. 


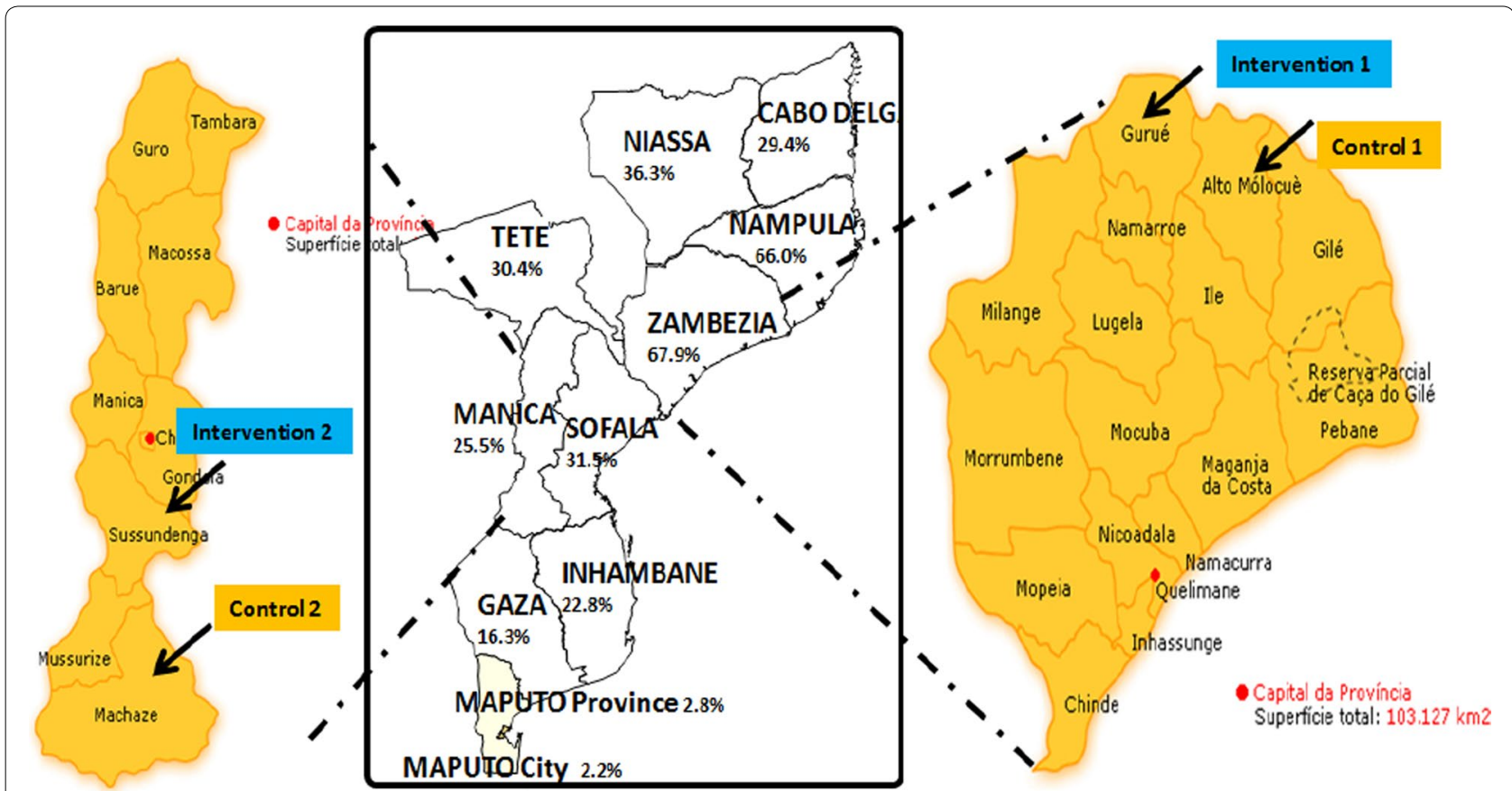

Fig. 1 Malaria prevalence in Mozambique and intervention and control districts of the study

\section{Description of the implementation strategies}

Multifaceted implementation strategies were designed and improved stage-by-stage. These implementation strategies were divided into two components: core/essential components and additional/complementary components. Three core components were designed and tested in the intervention districts: (i) use of coupons during household registration phase; (ii) use of stickers to identify the registered households; and (iii) a new criterion for LLIN allocation (one LLIN for every two persons). These three implementation strategies were developed and tested in Stage I. Household registration in the previous model (control districts) was undertaken without the use of coupons or stickers to identify the registered households, and variables such as name, age, gender, and family relationship of household members were collected and later analysed regarding possible sleeping patterns. The sleeping patterns were the LLIN ascription criteria (Table 1).

Three complementary components were added and implemented: (i) mapping and micro-planning (improvements added in Stage II); (ii) training; and (iii) support supervisions. Table 1 summarizes the implementation strategies during Stage I and II.

\section{Coupons}

The coupons have two parts, the stub, which is for control, and the ticket, which is given to the registered household members. Identical information appears on both the ticket and the stub. The coupon includes a single pre-enumeration area, background image (watermark) of a mosquito net, and information about the province, district, community, name of head of household, name of head of community, number of household members, number of LLIN to benefit, and the name of the distribution points (Fig. 2). The coupon is then later exchanged for the corresponding number of LLINs in the distribution phase.

\section{Sticker}

The sticker has information about the province, district, town, community, registration date, and the name of the registrar, along with a background image (watermark) of a mosquito net (Fig. 3).

\section{Long-lasting insecticidal nets ascription criterion}

The LLIN ascription criterion was one LLIN for every two persons (rounded up in case of decimal number) with a maximum (cap) of four LLIN per household, i.e., families with nine or more household members received four LLINs. This LLIN capping criterion was established only in one district in Stage II.

\section{Mapping and micro-planning}

Before mapping and micro-planning each district was given a list of data to be collected. This included 


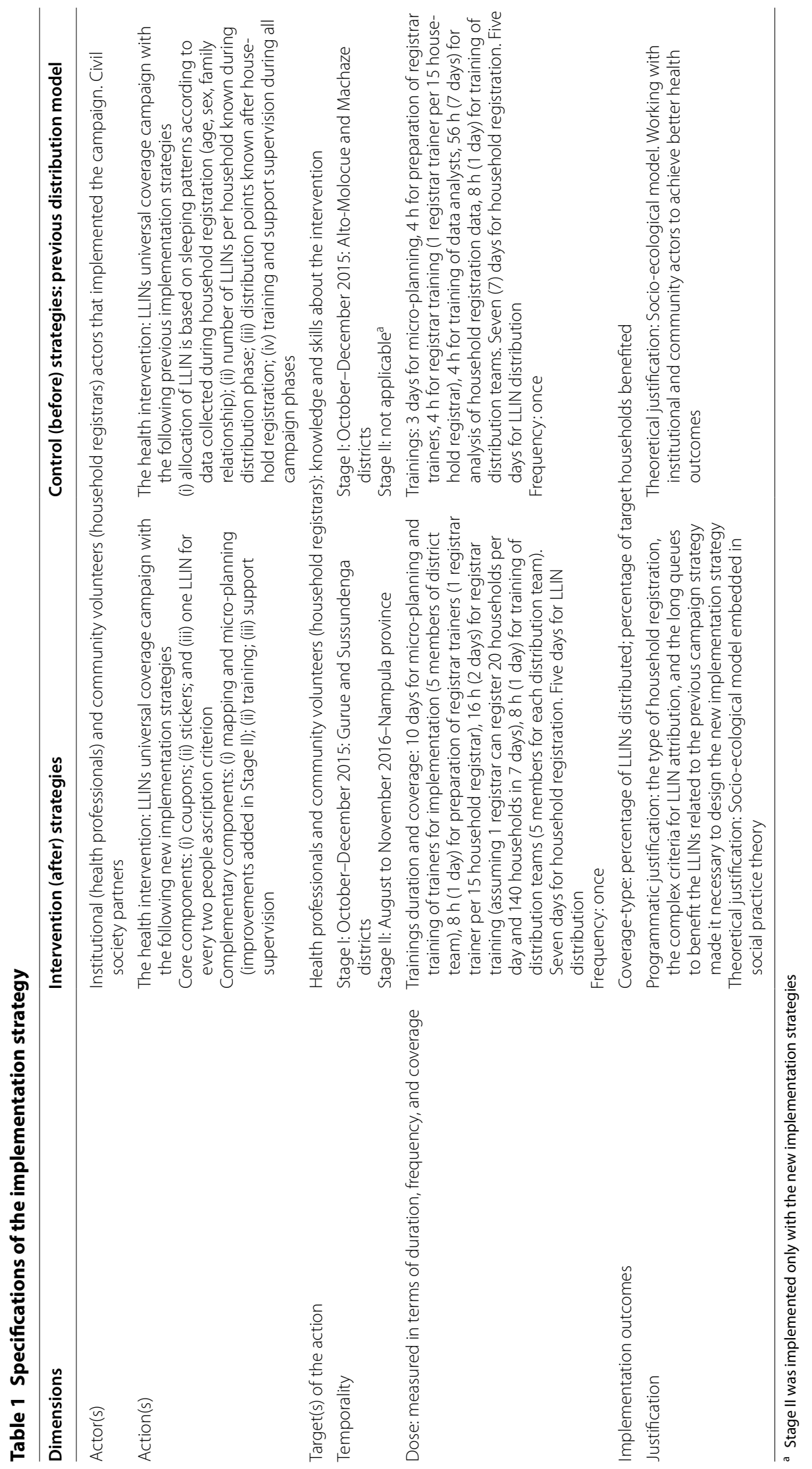




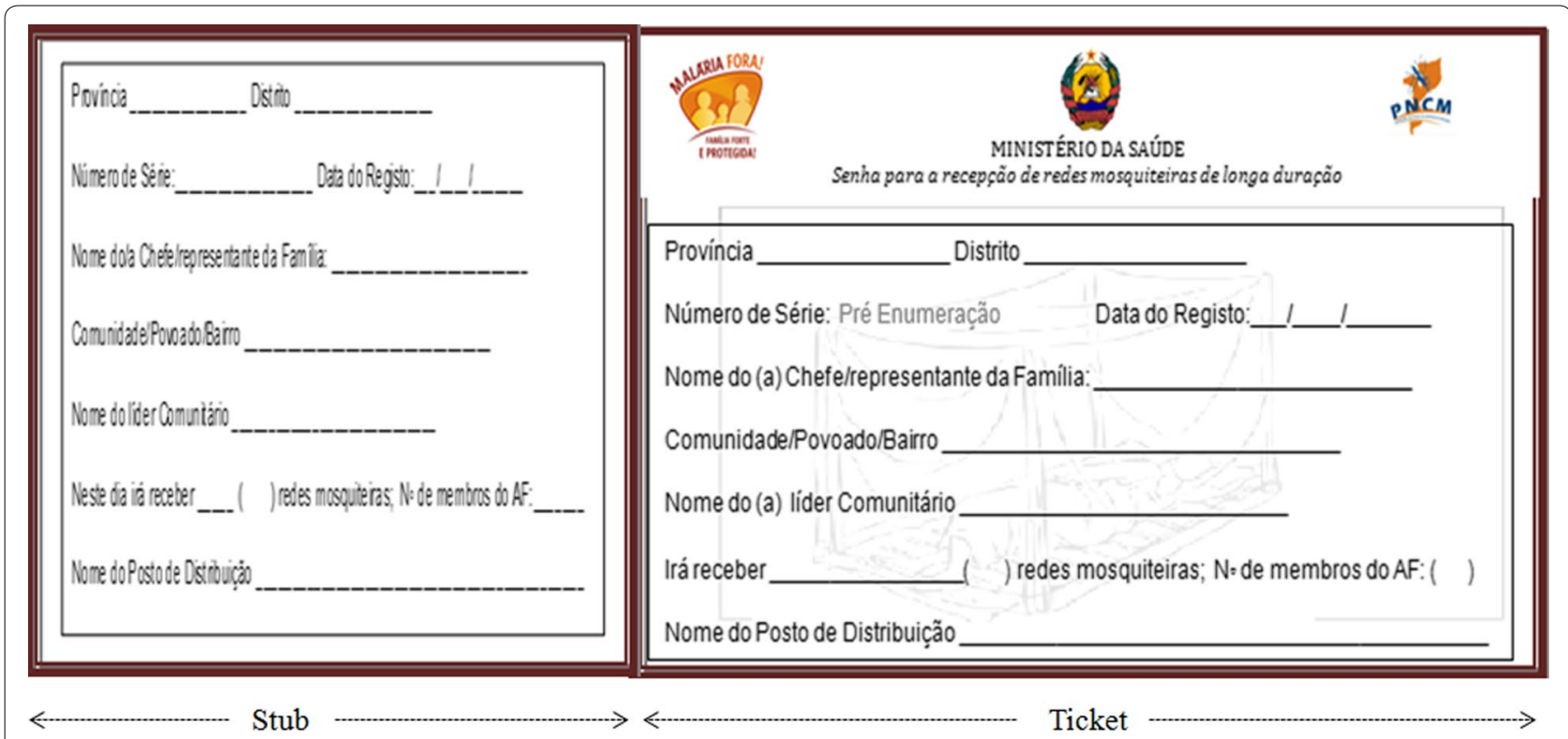

Fig. 2 Coupon for household registration

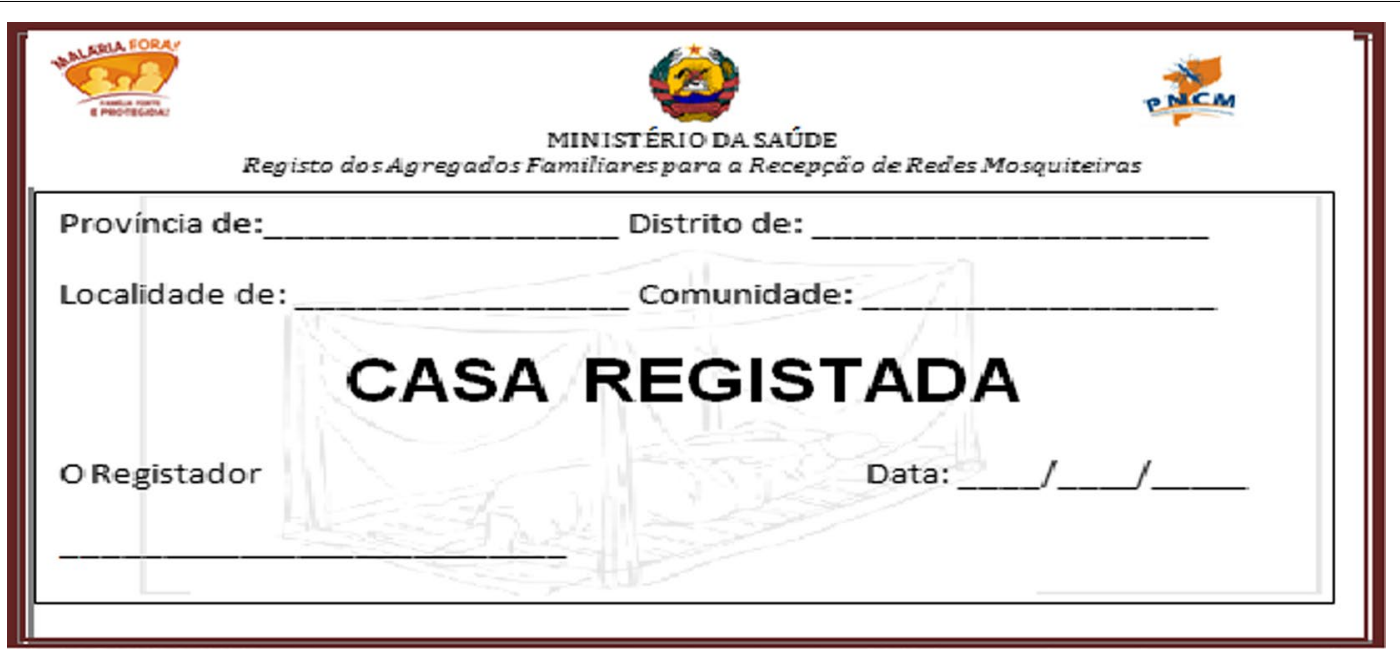

Fig. 3 Stickers to identify the registered households

population by each locality and administrative post, existing health and school infrastructures, sanctuaries, formal and informal markets, warehouses, distances map, roads, bridges, and remote zones of difficult access. This information is gathered onto a map that allows performing the micro-planning.

The micro-planning process uses a Microsoft office excel $^{\circledR}$ based tool with the following components: (i) position micro-plan; (ii) household registration plan; (iii) transport information; (iv) distribution plan; (v) transport plan; and (vi) crucial materials needed for registration and distribution. It is an iterative tool that allows easily identifying: (i) the population in each district by localities and communities; (ii) the warehouse that will serve each distribution point; (iii) number of LLINs and bales needed for each distribution point; (iv) number of household registrars needed for household registration process in a particular set of communities; (v) number and type of vehicles needed to transport LLINs from the main district warehouse to satellite warehouses (those located at community level) or distribution points; (vi) number of teams needed to distribute the LLINs in 5 days; and (vii) quantities of crucial materials needed for household 
registration and distribution phases. The tool is available as Additional file 1: Appendix 1.

\section{Training}

Two training of trainers (ToT) actions were carried out at the central level. The first and second ToT were conducted between August and September 2016 in order to prepare all National Malaria Control Programme (NMCP) key staff and civil society partners, namely: World Vision International (WVI), Malaria Consortium, Food for the Hungry association, and Foundation for the Community Development.

A cascade of trainings followed the central level ToT, namely: (i) micro-planning and implementation ToT; (ii) training for household registration phase; and (iii) training of distribution teams and satellite warehouse keepers. During the micro-planning and implementation ToT (carried out at provincial level) several topics are covered, such as: (i) mapping process; (ii) micro-planning process; (iii) rationale of the new UCC implementation strategies; (iv) logistics (direct and reverse logistics related to LLINs); (v) household registration process (including quality control); (vi) communication aspects related to UCC; and (vii) LLIN distribution organization process.

\section{Support supervision}

Support supervision is a critical implementation strategy that follows the mapping and micro-planning at provincial and district level. One provincial-level supervisor per district was assigned to support the UCC implementation. These supervisors (also called mentors) have the role of ensuring that all processes are carried out as planned (high fidelity) in their district. A structured supervision team was established at the district level and included: (i) a coordination group of five elements (district health team trained during micro-planning); and (ii) one supervisor for each 15 household registrars. Additionally, an action-checklist was developed in order to ensure appropriate support supervision process by central, provincial, and district supervisor teams.

\section{Outcomes and statistical analysis}

A coverage-type implementation outcome was used as primary expected outcome in Stages I and II:

- Percentage of LLIN distributed calculated as number of distributed LLINs/number of planned LLINs $\times 100$; the planned LLIN was determined by dividing the number of people by 1.78 (rounded up to 1.8 ) [18];

- Percentage of target households benefited calculated as number of households that received LLINs/number of registered households $\times 100$.
All registered households were considered as the denominator for determining household coverage. Since it was a before-and-after design, odds ratio and 95\% confidence interval were used to compare and establish differences between intervened and control districts. Implementation effectiveness was also calculated in Stage I to measure the extent of differences between intervention and control districts' implementation outcomes. Implementation effectiveness measure was chosen as it reflects "effectiveness" in implementation studies, i.e., the equivalent of efficacy under "real world" implementation conditions. According to Gupta [19], implementation effectiveness or effectiveness at strategy implementation should be measured in the form of comparison between actual performance and a priori expectations rather than on an absolute scale.

- Implementation effectiveness $=$ (outcome proportion with new implementation strategy-outcome proportion with previous implementation strategies $) \times 100 /$ outcome proportion with previous implementation strategies.

The WINPEPI [20] version 11.60 computer programs were used for statistical analysis. For all statistical procedures, a 0.05 significance level was adopted for rejecting the null hypothesis.

In Stage II (Nampula province LLIN UCC implementation) only administrative data are reported using absolute frequency for registered households and distributed LLINs. Percentage of households benefited, and percentage of distributed LLIN were calculated. There were no control districts or provinces at this stage.

\section{Results}

Stage I

Household registration results revealed an existence of 136,985 and 120,446 households in the intervention and control districts, respectively. These household registration results also revealed a need for 344,770 and 284,873 LLINs in the intervention and control districts, respectively.

Nearly $88 \%(302,648)$ of planned LLINs were distributed in the intervention districts (Gurue and Sussundenga) compared to $77 \%(219,613)$ in the control districts (Alto Molocue and Machaze), with an implementation effectiveness of $12.2 \%$ [OR: 2.14 (95\% CI 2.11-2.16; $\mathrm{p}<0.001)$ ]. Also, Stage I results revealed that $80.6 \%$ $(110,453)$ of households received at least one LLIN in the intervention districts compared to $72.8 \%(87,636)$ households in the control districts with an implementation effectiveness of 9.8\% [OR: 1.56 (95\% CI 1.53-1.59); $\mathrm{p}<0.001]$. 


\section{Stage II}

In Stage II (massive pilot in Nampula province) microplanning figures revealed a total of 5,638,667 inhabitants and 1,282,512 households. After household registration these figures increased to a total of 7,038,427 inhabitants (24.8\% increase) and 1,373,002 households (7.1\% increase) (Table 2). During LLIN distribution several districts retrieved more coupons than what had been delivered (fake coupons). The most impressive case of this was in Mossuril district, where 47,231 out of 25,969 delivered coupons were retrieved (Table 2). Despite this, 3,536,839 LLINs (98.4\% of the allocated LLINs) were delivered, covering 1,353,827 households (98.6\% of the registered households).

\section{Discussion}

Stage I and II results shows that more LLINs were distributed and more households benefitted as a result of the new implementation strategies. This might be attributed to the coupons and sticker implementation strategy. The coupons seem to have had the desired effect, namely: (i) ensured the necessary confidence for the households that will in fact receive LLINs; (ii) identified the distribution point that households should go to in order to obtain LLINs; and (iii) facilitated confirmation that the household was registered, i.e., during LLINs distribution phase, the coupon was exchanged for LLINs. This chain of events, which constitutes a positive gradient of demand behaviour, is here termed as "the coupon effect". This effect has also been observed in other studies in which coupons or vouchers were used [10-15]. Another explanation is that at the time of registering households a sticker was installed to identify registered houses. In this way, unregistered households were easily identified and registered, thereby ensuring that more households are registered and can benefit from LLINs. This additional factor is referred to herein as "the sticker effect". The combination of these factors (coupon and sticker effect), which encourages the target households to obtain the LLINs and determines their greater ownership, constitute what will be called herein "the coupon-sticker effect".

During a wrap up meeting held in early December 2016, with the main stakeholders involved in the Stage II massive pilot implementation, several weaknesses

Table 2 Population, households and coupons delivered and retrieved during Stage II

\begin{tabular}{|c|c|c|c|c|c|c|c|c|c|}
\hline \multirow[t]{2}{*}{ Districts } & \multicolumn{3}{|l|}{ Population } & \multicolumn{3}{|l|}{ Households } & \multicolumn{3}{|l|}{ Coupons } \\
\hline & After micro-planning & After HHR & $\%$ & After micro-planning & After HHR & $\%$ & Delivered & Retrieved & $\%$ \\
\hline Angoche & 446,064 & 612,491 & 37.3 & 83,049 & 107,960 & 30.0 & 107,890 & 84,049 & 77.9 \\
\hline Liupo & 105,617 & 140,236 & 32.8 & 20,469 & 24,613 & 20.2 & 24,613 & 26,548 & 107.9 \\
\hline Mecuburi & 197,275 & 208,387 & 5.6 & 46,851 & 49,001 & 4.6 & 49,131 & 44,942 & 91.5 \\
\hline Memba & 295,251 & 385,672 & 30.6 & 66,504 & 73,291 & 10.2 & 73,341 & 66,855 & 91.2 \\
\hline Mogincual & 113,717 & 146,330 & 28.7 & 21,220 & 25,904 & 22.1 & 25,953 & 21,699 & 83.6 \\
\hline Mogovolas & 674,001 & 491,777 & -27.0 & 112,011 & 122,283 & 9.2 & 107,387 & 76,958 & 71.7 \\
\hline Moma & 137,331 & 276,859 & 101.6 & 72,297 & 51,655 & -28.6 & 50,146 & 49,923 & 99.6 \\
\hline Murrupula & 212,692 & 425,973 & 100.3 & 44,261 & 75,055 & 69.6 & 75,914 & 39,230 & 51.7 \\
\hline Nacaroa & 150,588 & 206,577 & 37.2 & 31,753 & 41,400 & 30.4 & 40,714 & 33,663 & 82.7 \\
\hline Rapale & 179,362 & 230,600 & 28.6 & 72,889 & 44,992 & -38.3 & 44,992 & 45,229 & 100.5 \\
\hline Ribaue & 314,615 & 306,341 & -2.6 & 66,077 & 59,375 & -10.1 & 59,108 & 59,796 & 101.2 \\
\hline Nampula & 746,638 & 789,361 & 5.7 & 159,633 & 155,854 & -2.4 & 155,854 & 160,094 & 102.7 \\
\hline Erati & 329,681 & 472,101 & 43.2 & 79,140 & 94,714 & 19.7 & 94,583 & 89,977 & 95.1 \\
\hline Ilha Moz & 55,890 & 94,071 & 68.3 & 13,973 & 15,361 & 9.9 & 15,361 & 14,380 & 93.6 \\
\hline Lalaua & 79,341 & 149,018 & 87.8 & 22,206 & 27,184 & 22.4 & 27,184 & 27,873 & 102.5 \\
\hline Larde & 83,967 & 126,257 & 50.4 & 20,630 & 22,504 & 9.1 & 22,504 & 20,806 & 92.5 \\
\hline Malema & 197,836 & 234,028 & 18.3 & 49,459 & 48,864 & -1.2 & 48,864 & 49,630 & 101.6 \\
\hline Meconta & 190,279 & 253,867 & 33.4 & 48,635 & 52,089 & 7.1 & 52,089 & 49,987 & 96.0 \\
\hline Monapo & 402,534 & 556,372 & 38.2 & 95,612 & 116,503 & 21.8 & 115,197 & 109,665 & 95.2 \\
\hline Mossuril & 178,671 & 143,044 & -19.9 & 35,020 & 25,969 & -25.8 & 25,969 & 47,231 & 181.9 \\
\hline Muecate & 116,606 & 170,657 & 46.4 & 29,002 & 31,337 & 8.1 & 31,337 & 31,942 & 101.9 \\
\hline Nacala Porto & 293,931 & 437,379 & 48.8 & 60,944 & 72,889 & 19.6 & 72,889 & 75,236 & 103.2 \\
\hline NacalaVelha & 136,780 & 181,029 & 32.4 & 30,877 & 34,205 & 10.8 & 34,205 & 35,537 & 103.9 \\
\hline Total & $5,638,667$ & $7,038,427$ & 24.8 & $1,282,512$ & $1,373,002$ & 7.1 & $1,355,225$ & $1,261,250$ & 93.1 \\
\hline
\end{tabular}

HHR household registration 
were reported, and can be summarized in three critical features: coordination, planning, and some loss of implementation fidelity.

Coordination at provincial and district levels were not well established, leading to incomplete readiness and UCC preparation. The planning process (the microplanning tool) was not finalized, leading to deficiencies in the implementation process. Not establishing a cap (i.e. maximum LLIN per household) also led to inflation in the reporting of number of household members (population increase of $25 \%$ between micro-planning and after household registration figures without corresponding increase in households). This happened because the households realized that increasing the number of household members would benefit them with more LLINs. Another factor contributing to this inflation was the poor quality of the coupons, leading to coupon counterfeiting.

Implementation challenges are always present in the "real world". The goal is not to eliminate the implementation challenges (a nearly impossible task) but to reduce them sufficiently to implement the strategy with high fidelity. Only by understanding and measuring whether an intervention has been implemented with fidelity can researchers and practitioners gain a better understanding of how and why an intervention works, and the extent to which outcomes can be improved [21]. In fact, some loss of fidelity was noted during the Stage II implementation process, resulting in several constraints, as reported in the results section. However, if a high fidelity level is not achievable, ensuring adequate adaptation of the strategy to fit the local context should at least be attained. In order to ensure effectiveness of the implementation, adaptation may occur with complementary components, but fidelity is mandatory for the core components, i.e., ensuring high quality availability of coupons and stickers, and ensuring application of the new formula (one LLIN for every two people with a cap of four LLINs per household). An additional and required adaptation of the strategies is the introduction of independent monitoring of the household registration, in order to promptly detect errors and correct them during this critical UCC phase.

\section{Conclusions}

Stage I results showed greater availability and coverage of target households with LLIN in districts with the newly implemented strategies. The results of Stage II were also encouraging despite some problems related to population inflation and the quality of the coupons produced. Implementation strategies are important for reaching an effective health outcome. The importance of defining core and complementary components of a multifaceted implementation strategy resides in ensuring fidelity of the core components, and eventual adaptation of the complementary components to suit the local context. For the country-wide UCC some adaptation of the strategies is required, such as: ensuring high quality production of the coupons and stickers, capping the number of LLINs per household, and introducing independent monitoring of the household registration.

\section{Additional file}

Additional file 1: Appendix 1. Micro-planning tool.

\section{Abbreviations \\ AMP: Alliance for Malaria Prevention; Cl: confidence interval; HHR: household registration; LLIN: long-lasting insecticidal nets; NMCP: National Malaria Control Programme; OR: odds ratio; ToT: training of trainers; UCC: universal coverage campaign; WVI: World Vision International.}

\section{Authors' contributions}

JAHA conceived and designed the protocol, led the implementation process during Stages I and II, participated in the trainings, performed data analysis, and wrote the manuscript. LP led the implementation process during Stage II and reviewed the manuscript. CM participated in data analysis and supported critical manuscript review. BC coordinated the universal coverage campaign implementation process during Stages I and II. JP critically reviewed the manuscript. MROM supported the protocol design and data analysis and contributed to manuscript writing. All authors read and approved the final manuscript.

\section{Author details}

${ }^{1}$ World Vision International, Maputo, Mozambique. ${ }^{2}$ National Malaria Control Programme, Maputo, Mozambique. ${ }^{3}$ Global Health and Tropical Medicine, GHTM, Instituto de Higiene e Medicina Tropical, IHMT, Universidade Nova de Lisboa, UNL, Rua da Junqueira 100, 1349-008 Lisbon, Portugal.

\section{Acknowledgements}

The authors would like to acknowledge all the National Malaria Control Programme health professionals at central, provincial, and district levels involved in Stages I and II, especially the contributions of the anonymous community members during the implementing process. We also would like to acknowledge AMP for the technical support during Stage II and Stage III preparation. We are also grateful to Malaria Journal reviewers for fruitful comments.

\section{Competing interests}

The authors declare that they have no competing interests.

Availability of data and materials

Additional materials are available as Additional file 1: Appendix 1.

\section{Consent for publication}

Not applicable.

\section{Ethics approval}

The Stage I study was administratively authorized by the Provincial Health Departments of Zambezia (Ref 2270/DPSZ/512/2015) and Manica (09/11/2015), and also received authorization from the National Committee on Bioethics in Health (Ref 112/CNBS/2015).

Not applicable to Stages II and III.

\section{Funding}

The LLIN universal coverage campaign in Mozambique is supported through a financial contribution of Global Fund to fight AIDS, Tuberculosis, and Malaria.

\section{Publisher's Note}

Springer Nature remains neutral with regard to jurisdictional claims in published maps and institutional affiliations. 
Received: 24 June 2017 Accepted: 23 October 2017

Published online: 25 October 2017

\section{References}

1. WHO Global Malaria Programme. World malaria report. Geneva, World Health Organization; 2016. http://www.who.int/malaria/publications/ world-malaria-report-2016/en/. Accessed 19 Sept 2017.

2. Ministério da Saúde (MISAU), Instituto Nacional de Estatística (INE), ICF Internacional, 2015. Inquérito de Indicadores de Imunização, Malária e HIV/SIDA em Moçambique 2015. Maputo, Moçambique. Rockville, Maryland, EUA: INS, INE e ICF International.

3. Lengeler $C$. Insecticide-treated bed nets and curtains for preventing malaria. Cochrane Database Syst Rev. 2004;2:CD000363.

4. Gamble CL, Ekwaru JP, ter Kuile FO. Insecticide-treated nets for preventing malaria in pregnancy. Cochrane Database Syst Rev. 2009;2:CD003755.

5. Hawley WA, Phillips-Howard PA, ter Kuile FO, Terlouw DJ, Vulule JM, Ombrok M, et al. Community-wide effects of permethrin-treated bed nets on child mortality and malaria morbidity in western Kenya. Am J Trop Med Hyg. 2003;68:121-7

6. Global strategic plan. Roll back malaria 2005-2015. Geneva: Roll Back Malaria Partnership; 2005.

7. Bennett A, Smith SJ, Yambasu S, Jambai A, Alemu W, Kabano A, et al. Household ownership and use of insecticide-treated mosquito nets in Sierra Leone 6 months after a national mass-distribution campaign. PLoS ONE. 2012;7:e37927.

8. Walker PGT, Griffin JT, Ferguson NM, Ghani AC. Estimating the most efficient allocation of interventions to achieve reductions in Plasmodium falciparum malaria burden and transmission in Africa: a modelling study. Lancet Glob Health. 2016:4:e474-84.

9. Winskill P, Walker PGT, Griffin JT, Ghani AC. Modeling the cost effectiveness of introducing the RTS, S malaria vaccine relative to scaling up other malaria interventions in sub-Saharan Africa. BMJ Global Health. 2017:2:e000090.

10. Krezanoski PJ, Comfort AB, Hamer DH. Effect of incentives on insecticidetreated bed net use in sub-Saharan Africa: a cluster randomized trial in Madagascar. Malar J. 2010;9:186.
11. Renggli S, Mandike R, Kramer K, Patrick F, Brown NJ, McElroy PD, et al. Design, implementation and evaluation of a national campaign to deliver 18 million free long-lasting insecticidal nets to uncovered sleeping spaces in Tanzania. Malar J. 2013;12:85

12. Stevens ER, Aldridge A, Degbey Y, Pignandi A, Dorkenoo MA, HugelenPadin J. Evaluation of the 2011 long-lasting, insecticide-treated net distribution for universal coverage in Togo. Malar J. 2013;12:162.

13. Thwing Jl, Perry RT, Townes DA, Diouf MB. Success of Senegal's first nationwide distribution of long-lasting insecticide-treated nets to children under five-contribution toward universal coverage. Malar J. 2011;10:86.

14. Tokponnon FT, Ahoulokpe B, Denon EY, Gnanguenon V, Bokossa A, N'guessan R, et al. Evaluation of the coverage and effective use rate of long-lasting insecticidal nets after nation-wide scale up of their distribution in Benin. Parasit Vectors. 2013;6:265

15. West PA, Protopopoff N, Rowland MW, Kirby MJ, Oxborough RM, Mosha $F W$, et al. Evaluation of a national universal coverage campaign of longlasting insecticidal nets in a rural district in north-west Tanzania. Malar J. 2012;11:273.

16. Instituto Nacional de Estatística. Relatório Final do Inquérito ao Orçamento Familiar-IOF 2014/15. http://www.ine.gov.mz/operacoesestatisticas/inqueritos/inquerito-sobre-orcamento-familiar/relatorio-finaldo-inquerito-ao-orcamento-familiar-iof-2014-15/view. Accessed 20 May 2017.

17. Arroz JAH. Increase in cases of malaria in Mozambique, 2014: epidemic or new endemic pattern? Rev Saude Publica. 2016;50:5

18. Kilian A, Boulay M, Koenker $\mathrm{H}$, Lynch $\mathrm{M}$. How many mosquito nets are needed to achieve universal coverage? Recommendations for the quantification and allocation of long-lasting insecticidal nets for mass campaigns. Malar J. 2010;9:330.

19. Gupta AK, Govindarajan V. Business unit strategy, managerial characteristics, and business unit effectiveness at strategy implementation. Acad Manag J. 1984;27:25-41.

20. Abramson JH. WINPEPI updated: computer programs for epidemiologists, and their teaching potential. Epidemiol Perspect Innov. 2011:8:1.

21. Carroll C, Patterson M, Wood S, Booth A, Rick J, Balain S. A conceptual framework for implementation fidelity. Implement Sci. 2007:2:40.

\section{Submit your next manuscript to BioMed Central and we will help you at every step:}

- We accept pre-submission inquiries

- Our selector tool helps you to find the most relevant journal

- We provide round the clock customer support

- Convenient online submission

- Thorough peer review

- Inclusion in PubMed and all major indexing services

- Maximum visibility for your research

Submit your manuscript at www.biomedcentral.com/submit
BioMed Central 